\title{
Metastatic Gastric Neuroendocrine Carcinoma
}

National Cancer Institute

\section{Source}

National Cancer Institute. Metastatic Gastric Neuroendocrine Carcinoma. NCI

Thesaurus. Code C156682.

A gastric neuroendocrine carcinoma that has spread from its original site of growth to another anatomic site. 